\title{
Correlations for Evaluation of Flame Spread over an Inclined Fuel Surface
}

\author{
XINYAN HUANG ${ }^{1}$ and MICHAEL J. GOLLNER ${ }^{2}$ \\ ${ }^{1}$ Department of Mechanical Engineering \\ Imperial College London \\ London,SW7 2AZ, UK \\ ${ }^{2}$ Department of Fire Protection Engineering \\ University of Maryland \\ College Park, MD 20742, USA
}

\begin{abstract}
The time-dependent flame spread process over thermally thick slabs of polymethyl methacrylate (PMMA) is investigated with particular emphasis on the burning behavior and geometry of the flame. $10 \mathrm{~cm}$ wide by $20 \mathrm{~cm}$ long samples are ignited and allowed to spread upwards at angles of orientation between pool and ceiling burning. Correlations between the flame length and the fuel mass-loss rate have revealed a delayed transition to turbulence for flames residing on the underside of fuel samples, and an earlier transition to turbulence for flames on the topside of these samples, compared to traditional vertical wall flames. As the fuel inclination increases, the relationship between the flame length and fuel mass-loss rate ranges between a recent theoretical prediction for a laminar wall plume dominated by diffusion and the traditional prediction for a turbulent wall plume dominated by convective mixing. The buoyancy-induced flow field, characterized by the flame tilt angle is shown to correspond to previously-found modifications of heat-flux profiles ahead of the flame front, which control flame spread, and the heat flux to the burning surface of the fuel, which controls fuel mass-loss rates. Other correlations between some of these parameters, such as the flame and pyrolysis lengths are also presented as a function of inclination.
\end{abstract}

KEYWORDS: upward flame spread, inclined fuel, flame geometry, PMMA, wildfires

\section{NOMENCLATURE LISTING}
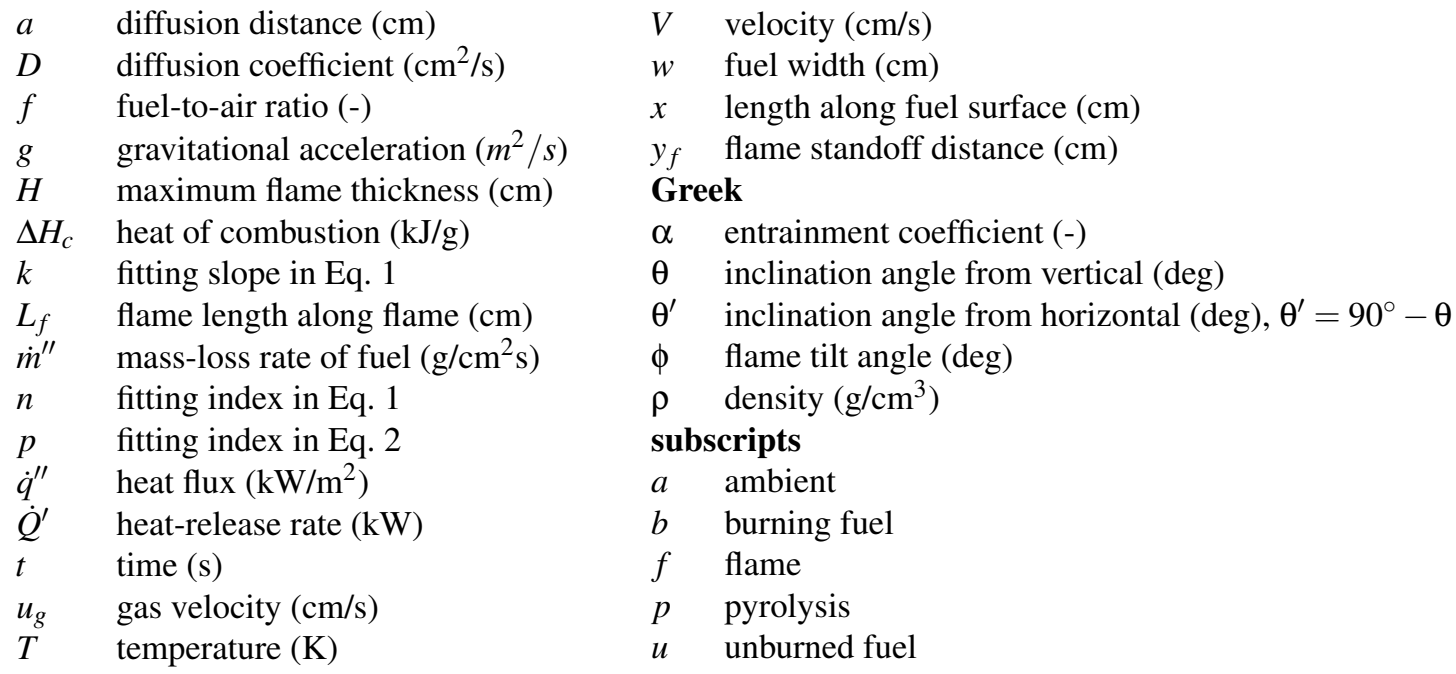

\section{INTRODUCTION}

Flame spread over inclined fuels is a common fire-hazard scenario, however it has received much less attention in the literature than vertical $[1,2]$ or horizontal [3] flame spread. This work will focus on upward flame spread, the rates of which are much higher than counter-current downward flame spread [4]. Two practical scenarios have motivated the majority of the work conducted on the topic. In the built environment, a tragic fire up a wooden escalator in King's Cross Station, London brought attention to an inclined spread 
scenario. This geometry was special, where the sidewalls of a wooden escalator restricted air entrainment to be perpendicular to the trench, pushing flames close to the fuel surface and rapidly accelerating flame spread to devastating effect (i.e. "trench effect"), which inspired many studies (e.g. [5, 6, 7]) for comparison with uninhibited inclined flame spread. Beyond the built environment, wildland fires often spread over sloped fuel surfaces, and some attention has been devoted to studying them [8]. Of particular interest is flame attachment, the transition where flames rest closer to the fuel surface and spread accelerates rapidly. Knowledge of flame geometry can be useful to model inclined wildland fire spread, as radiation-dominated flame spread will be influenced by the view factor between the flame and unignited fuel and convective-dominated flame spread will be greatly accelerated when flames are attached closer to the fuel surface [9]. Some standard industry tests, such as ASTM E108 [10] use an inclined configuration over a roof, which may also be better understood as a result of this work.

Kashiwagi and co-workers reported some early measurements of inclined flame spread over (thermally) thin cellulose sheets [11] and thick PMMA slabs [12]. Drysdale and Macmilliam systematically measured the flame-spread rate at different orientations, $\theta=0^{\circ} \sim 90^{\circ}$, utilizing both thick PMMA and thin computer cards [5]. Pizzo et al. [13] and Xie and DesJardin [14] further investigated flame spread over the surface of PMMA in the same range, employing both experiments and numerical simulations. For boundary-layer flame spread over thermally-thin fuels, Quintiere [15] developed a flame-spread theory using a modified Grashof number to account for gravity along with heat-transfer correlations from Ahmad and Faeth [16] and Roper et al. [17], agreeing with experimental results qualitatively.

Recent experiments by Zhang et al. [18] on small burning wicks found the orientation of maximum burning rate around $\theta=45^{\circ} \sim 60^{\circ}$, and they presented a theoretical formulation to describe this phenomena by modifying the theory of Ahmad and Faeth [16] adding a cross-flow buoyancy normal to the plate. Numerical studies by Ali et al. $[19,20]$ also revealed that the maximum standoff distances and heat fluxes to the fuel surface occurs at inclinations of $\theta=30^{\circ} \sim 45^{\circ}$, corresponding to the largest mass-loss rates. These studies, however, do not agree with large gas-burner results [21] or experiments on $10 \mathrm{~cm} \times 20 \mathrm{~cm}$ samples of PMMA $[22,23]$, where fuel mass-loss rates reach a maximum as a pool-fire configuration is approached $\left(\theta=90^{\circ}\right.$ or $\theta^{\prime}=0^{\circ}$ ). In the PMMA experiments, this maximum mass-loss rate occurred at the same angle for both steady and spreading fires, however flame-spread rates followed a different trend, reaching a maximum near a vertical orientation. The source of this discrepancy lies with varying buoyancy-induced flows, modifying the flame geometry to provide different heat fluxes to the burning region and the unburned region, which controls the burning rate and the flame-spread rate, respectively.

$\mathrm{Wu}$ and Atkinson [6] used a porous gas burner on an unconstrained inclined surface to test the effects of varying heat-release rates on flame shape. They used a synthetic Schlieren system to detect the flame, which was described by a plume attachment length along the inert surface and a plume angle between the center of the flame and the inert surface. A critical angle of inclination found for flame attachment and rapid fire spread was $\theta=66^{\circ}$ (or $\theta^{\prime}=24^{\circ}$ ), defined where a large increase in plume attachment length was found. Their results were only presented for one geometry, a thin line burner, however their angle for critical flame attachment was close to gas burner results in trenches [24] and for flame spread over PMMA [5, 25]. Recently, Zhang et al. [26] experimentally found that the critical inclination angle for rapid flame acceleration is around $\theta=70^{\circ} \sim 80^{\circ}$ (or $\theta^{\prime}=10^{\circ} \sim 20^{\circ}$ ). Despite the fact that the flame separates from the fuel surface near $\theta>60^{\circ}$ [15], their theoretical analysis, which was based on an analytical expression from boundary-layer theory, agreed well with experimental results.

By inclining the thermally thick $(1.27 \mathrm{~cm})$ sample of polymethyl methacrylate (PMMA) at different angles of orientation from the vertical $(\theta$, see Fig. 1$)$, the authors previously found the maximum flame-spread rate occurred near a vertical orientation $\left(\theta=0^{\circ}\right)$ while the maximum burning rate occurred near a horizontal orientation $\left(\theta=90^{\circ}\right)[22,23]$. These experiments were controlled by a buoyantly-induced flow field, where the flame shape is modified by both entrained air velocities and the buoyant elevation of hot gasses.

This study focuses on the period of rapid flame spread over a wide range of inclinations $\left(\theta=-60^{\circ} \sim 60^{\circ}\right)$, outside the well-studied slow-spread region near the critical inclination angle and before a steady-burning (non-spread) period. Since the burning area varies with time, the flame geometry and burning behavior are highly time-dependent, different from previously-studied near-line fires [6]. By carefully investigating the 

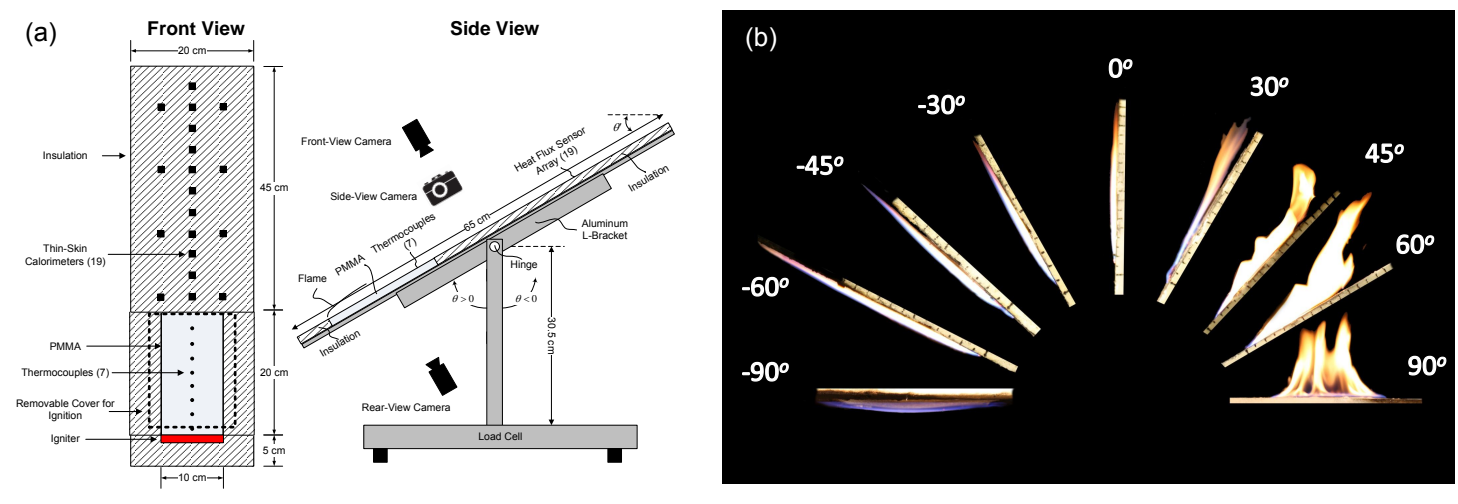

Fig. 1. (a) Experimental setup [22, 23], and (b) side-view image of the flame shape for $\theta=-90^{\circ} \sim 90^{\circ}$.

flame length, standoff distance, and tilt angle as a function of time, a detailed description of the flame geometry can be formed. This description can then be used to investigate previously-observed burning behaviors, such as spread and burning rates [23]. This series of experiments has been conducted without sidewalls, particularly in order to observe three-dimensional effects. These three-dimensional flows occur in many realistic inclined flame-spread scenarios and, despite different configurations and sizes, the observed trends should still remain valid, especially during the early-stage flame development.

\section{EXPERIMENTAL SETUP}

An experimental apparatus, similar to that in previous work [22, 23], was used to simultaneously measure mass-loss rates, flame-spread rates and the flame shape and dimension during flame spread on an inclined sample of PMMA, as illustrated in Fig. 1. A $1.27 \mathrm{~cm}$ thick, $10 \mathrm{~cm}$ wide, $20 \mathrm{~cm}$ tall sheet of Acrylite GP (PMMA) was mounted onto a rotateable inclined sheet of aluminum, with $1.27 \mathrm{~cm}$ thick ceramic fiber insulation extending $5 \mathrm{~cm}$ below, $5 \mathrm{~cm}$ to both sides and $45 \mathrm{~cm}$ downstream of the fuel surface, ensuring a continuous flat surface near the fuel sample. K-type thermocouples were melted onto the surface of the PMMA to measure the progression of the pyrolysis front and three cameras were placed around the sample to view the flame length, the flame-standoff distance, and bubbling, through the front, side, and rear of the sample, respectively. The load cell measured the mass of the sample at $15 \mathrm{~Hz}$ with an accuracy of $\pm 0.5 \mathrm{~g}$. Heat fluxes were measured with an array of thin-skin calorimeters on the insulation above the fuel, and more details are described elsewhere [22, 23].

Samples were ignited on the bottom by a small ceramic wick $(1 \mathrm{~cm}$ thick) soaked with $3 \mathrm{~mL}$ of methyl decanoate at a $60^{\circ}$ orientation from the horizontal. During ignition, the whole fuel surface, except for the bottom $2 \mathrm{~cm}$, was covered by a $6 \mathrm{~mm}$ thick sheet of ceramic insulation, avoiding preheating of the bulk fuel. This ensured all samples experienced the same ignition conditions, after which the sample was rotated to the desired angle of orientation and the insulation slab was removed. All tests were repeated between four to nine times to ensure repeatability of the experimental results.

\section{DESCRIPTION OF THE FLAME}

In this paper, the inclination angle, $\theta$, is defined as the angle formed between the fuel surface and the vertical $(\vec{g})$. As shown in Fig. $1, \theta>0$ denotes a fire above the fuel surface (a pool-type fire at $\theta=90^{\circ}$ ); $\theta<0$ denotes a fire below the fuel surface (a ceiling fire at $\theta=-90^{\circ}$ ); and $\theta=0^{\circ}$ is a vertical wall fire. Note that the current definition of inclination angle is the same as in Quintiere's pioneering work [15], but different from some other studies $[19,20]$, in which the inclination angle, $\theta^{\prime}$, is defined as the angle between the fuel surface and the horizontal with $\theta^{\prime}=90^{\circ}-\theta$. Figure $1 \mathrm{~b}$ shows instantaneous photographs of the side-view of spreading flames, which clearly illustrates the effect of inclination angle on flame shape. These photographs were all taken at different times, but at the same moment the pyrolysis front reaches the center of the fuel $\left(x_{p}=10\right.$ $\mathrm{cm}$ ), as measured by thermocouples on the surface of the fuel. For $\theta \leq 0^{\circ}$, the flame remains well-attached 


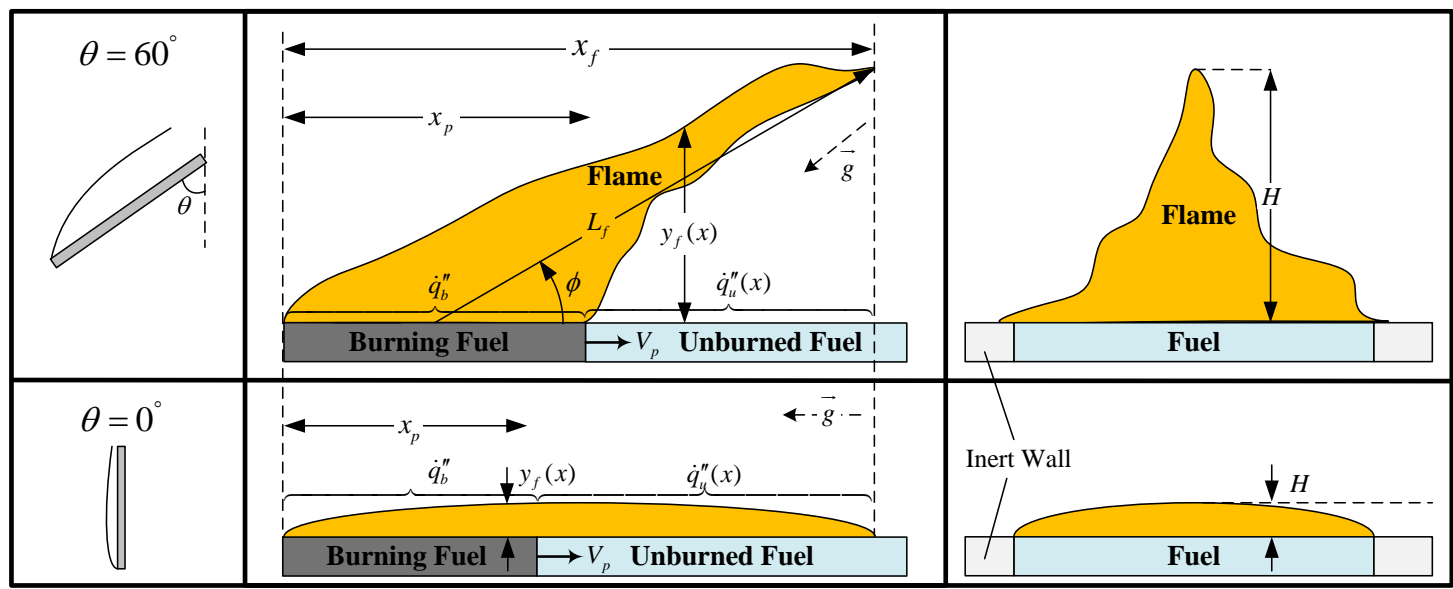

Fig. 2. Illustration showing definitions of the pyrolysis height, $x_{p}$, heat fluxes, $\dot{q}_{b}^{\prime \prime}$ and $\dot{q}_{u}^{\prime \prime}$, flame lengths, $L_{f} \&$ $x_{f}$, standoff distance, $y_{f}$, tilt angle, $\phi$, and three-dimensional behaviors of the flame at $\theta=0^{\circ}$ and $60^{\circ}$.

to the surface of the fuel within a boundary layer, and for $\theta>0^{\circ}$, it slowly lifts off the surface downstream of the leading edge, exhibiting more plume-like behavior and an increasing flame thickness with $x$ as $\theta$ is increased.

Figure 2 shows a conceptual picture of the flame geometry and associated parameters at $\theta=0^{\circ}$ and $60^{\circ}$. The pyrolysis length, $x_{p}$ is the length of the region of ignited fuel along the surface, and the flame length, $x_{f}$ is defined as the distance along the fuel surface where the flame resides perpendicularly above (i.e. the observed flame length in front view). This definition of flame length is slightly different from some other descriptions in wildland fires [27], where it is defined as the length between the center of pyrolyzing fuel and the flame tip, $L_{f}$. However, this definition proves to be more appropriate for some correlations developed in this study, where the flame length above the surface of unburned fuel is of interest, and the difference between $x_{f}$ and $L_{f}$ is small at a small tilt angle, $\phi$, defined later. The standoff distance (or local thickness) of the flame, $y_{f}(x)$ is defined as the distance between the flame sheet and fuel surface. The maximum flame thickness, $H$ occurs near the flame tip, $H=y_{f}\left(x_{f}\right)$ for a lifted flame and near the center of the flame along $x$ for boundary-layer flames (also see Fig. 1b).

The flame tilt angle is a useful parameter to describe plume-like behavior for separated boundary-layer flames, however its definition varies in the literature. Many definitions of flame tilt angle exist in both wildfire applications [27, 8] and studies of wind-blown pool fires [28]. Most of these studies define this angle by a line from the center of the burning region $\left(x_{p} / 2\right.$ in this case) to the tip of the flame, as shown in Fig. 2. Recent experiments of hydrocarbon pool fires under a forced flow described this angle by the probability of flame appearance to get relatively stable results [28]. All of these definitions could be similarly defined with reference to the horizontal or vertical rather than the fuel surface, as $\theta+\phi$ or $90^{\circ}-(\phi+\theta)$, respectively.

Heat flux parameters that result from the flame geometry and ultimately influence flame spread and burning are also indicated in Fig. 2. Here, $\dot{q}_{b}^{\prime \prime}$ is defined as the heat flux per unit area from the flame to the surface of the burning (fast pyrolyzing) fuel, which controls the mass-loss rate per unit area of the fuel, $\dot{m}^{\prime \prime}$, often referred as the burning rate. The heat flux from the flame per unit area to unburned (preheated) fuel ahead of $x_{p}$ is also shown, $\dot{q}_{u}^{\prime \prime}$, which controls flame-spread rates, defined as $V_{p}=d x_{p} / d t$. Previous work [22, 23] hypothesized that these two heat fluxes differ as $\theta$ varies, based on different observed trends in $\dot{m}^{\prime \prime}$ and $V_{p}$ with $\theta$ and measurements of $\dot{q}_{u}^{\prime \prime}$ to an inert surface above the fuel. 


\section{EXPERIMENTAL RESULTS AND DISCUSSIONS}

\section{Flame and Pyrolysis Lengths}

The pyrolysis length $x_{p}$ was measured by thermocouples melted onto the surface of the fuel, illustrated in Fig. 1a. The pyrolysis temperature, or threshold used to determine ignition of the fuel at a location was selected as $300^{\circ} \mathrm{C}$ based upon comparison of the rear-view observations of bubbling and previous measurements
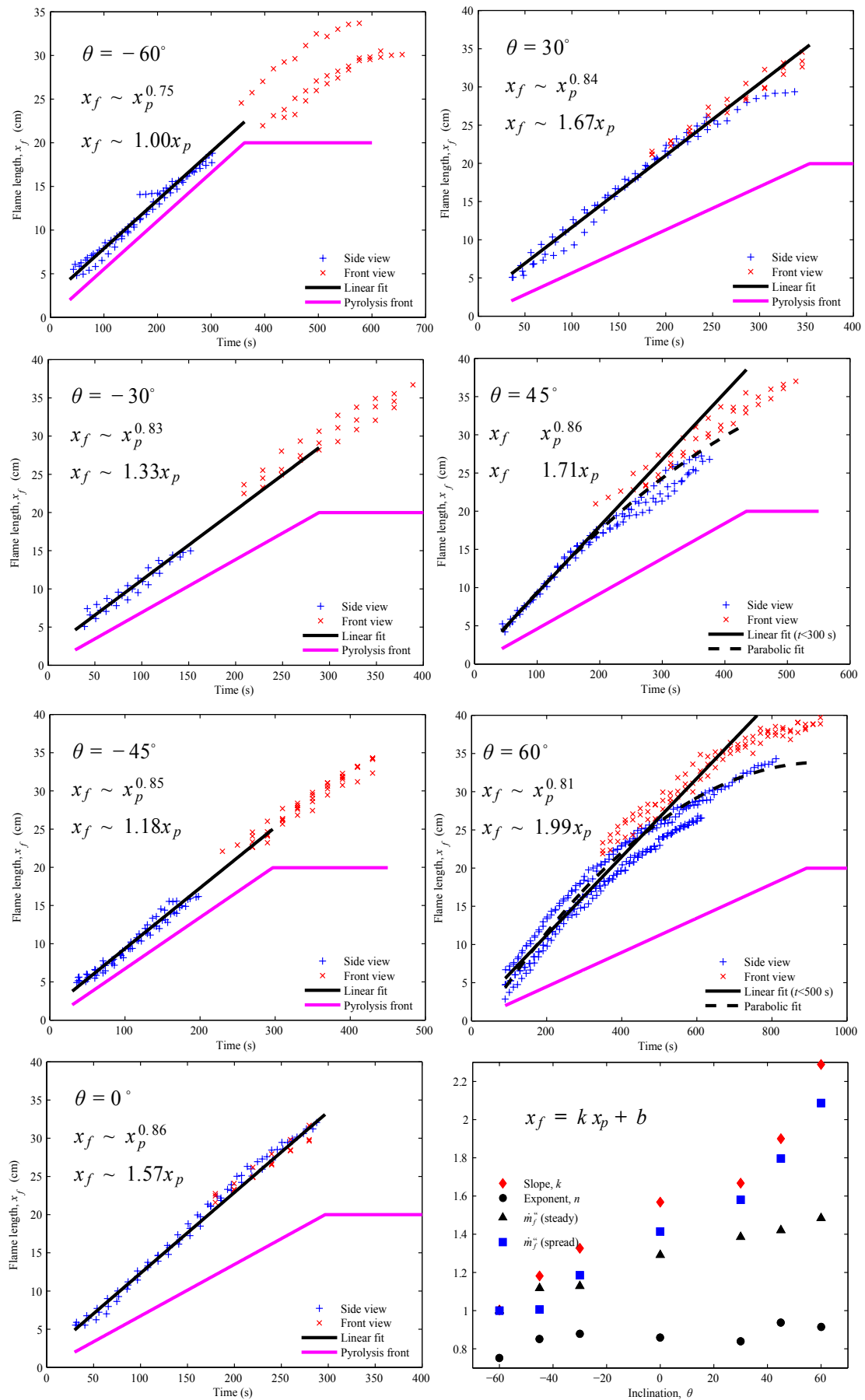

Fig. 3. (a-g) Flame and pyrolysis lengths as a function of time, where the bottom line indicates a linear fit to $x_{p}$ and symbols measurements of $x_{f}$ from front and side camera views, with the higher solid line a linear fit;

(h) the fitting index $n$ and slope $k$ in Eq. (1) compared with normalized burning rate from [23]. 
on Acrylite [2]. Over the short distances flames spread in this study $\left(x_{p}<20 \mathrm{~cm}\right)$, the pyrolysis front is approximately linear with time, so a linear fit through the thermocouple measurements at the point they reach a pyrolysis temperature is a good approximation. This assumption was tested for vertical flame spread over the sample and compared with results from an infrared camera and found to match within experimental errors [22]. Pyrolysis lengths formed by linear fits of experimental data, averaged between 4-9 tests for each inclination, are shown in Fig. 3a-g.

Flame contours were measured in two planes, one from a front-view camcorder recording at $30 \mathrm{fps}$ and also by a side-facing DSLR camera at $1 \mathrm{fps}$. It was important to use this lower-speed DSLR camera for the side view in order to have accurate focusing, resolving small flame-standoff distances at early times. The sacrifice in recording frequency, however, does make it more difficult to resolve statistical measures of the flame location. From the front-view, the camcorder observes the flame projection length along the fuel surface, $x_{f}$, and the averaged flame length of 30 frames was defined as $x_{f}$ for that second. Due to the interference of PMMA surface reflection, the front-view camera can only capture the flame contour when the flame length is past the top of the fuel, $x_{f}>20 \mathrm{~cm}$. A similar procedure was applied to side-view images by continuously averaging 10 photos, where flames correspondingly experienced less fluctuations with time, and small flame lengths at the beginning of spread can be measured. Both measurements showed small fluctuations, and the combination of them provides a good description of the flame length over time.

Figure 3a-g shows measured flame lengths from several repeated tests using both methods, with lower blue symbols $(+)$ determined from side-view images and higher red symbols $(\times)$ from front-view images. Despite different measurement techniques for flame lengths, they appear to match relatively well, even in the overlapping region for some tests. Comparison with heat-flux gauge regions where the flame length is determined by a threshold of $10 \mathrm{~kW} / \mathrm{m}^{2}$ also showed to agree well with front-view measurements [22]. It is clear in Fig. 3 that during initial semi-steady flame spread $(t<400 \mathrm{~s})$, a linear fit for the flame length is appropriate for all inclination angles. At $\theta=45^{\circ}$ and $60^{\circ}$, spread rates are much smaller and a parabolic fit may be better to describe the whole spread process (see dash line in Fig. 3f and g). The transition between flame spread and steady burning, where the thermal wave penetrates the depth of the fuel resulting in higher temperatures and thus higher burning rates is more complex than time-dependent spread and is not considered here.

The relationship between the flame length, $x_{f}$ and pyrolysis length, $x_{p}$ follows one of two common correlations,

$x_{f}=\left\{\begin{array}{l}A x_{p}^{n}, \\ k x_{p}+b,\end{array}\right.$

where the first expression and index $n$ are widely used for different fuels in upward flame spread [2, 29]. Additionally, since both $x_{p}$ and $x_{f}$ are approximated as linear functions in this work, a linear fit would also work well with a $y$-intercept $b$. Incorporating these two expressions in Eq. 1 increases the utility of constant parameters describing the flow, offering different means to describe the phenomena.

Values from the correlation coefficients, $k$ and $n$, are listed in Table 1 and plotted in Fig. $3 \mathrm{~h}$. Clearly, the slope $k$ increases with $\theta$, that is, the flame length over time increases more rapidly than pyrolysis lengths. On the other hand, at $\theta=0^{\circ}$ (a vertial wall fire), $n=0.86$ was found, close to the corresponding values of 0.78 [1] and 0.8 [30] for large-scale turbulent wall fires. More interestingly, the fitting index $n$ at $\theta=-45^{\circ} \sim 60^{\circ}$ is nearly a constant around 0.85 . The spread rate $V_{p}(\theta)$ during the early stage of a fire is a constant which depends only on the inclination angle [23], so the flame length increases with time as $x_{f} \sim t^{0.85}$ within the above range of inclinations. This result may be useful in simulating early-stage fires in complex configurations.

\section{Flame Length and Mass-Loss Rate}

Since the development of the classic Burke-Schumann approach [32], the characteristic diffusion flame length has often scaled by the burning rate, either $\dot{m}^{\prime}$ or $\dot{m}^{\prime \prime}$. A measurement of $\dot{m}^{\prime \prime}$, when the pyrolysis front just reaches the top of the sample $\left(x_{p}=20 \mathrm{~cm}\right)$, is reported in Table 1 , and the normalized value with respect to the minimum value at $\theta=-60^{\circ}$ is plotted in Fig. $3 \mathrm{~h}$ for comparison, where it increases with $\theta$ at almost the same slope as $k$. 
Table 1. Experimental results and fitting coefficients.

\begin{tabular}{ccccccc}
\hline$\theta$ & $V_{p}(\mathrm{~cm} / \mathrm{s})$ & $\dot{m}^{\prime \prime}\left(\mathrm{g} / \mathrm{cm}^{2} / \mathrm{s}\right)^{a}$ & $\dot{Q}^{\prime}(\mathrm{kW} / \mathrm{m})^{b}$ & $k$ & $n$ & $p$ \\
\hline$-60^{\circ}$ & 0.055 & 2.83 & 13.7 & 1.00 & 0.75 & 1.28 \\
$-45^{\circ}$ & 0.067 & 2.85 & 13.8 & 1.18 & 0.85 & 1.27 \\
$-30^{\circ}$ & 0.069 & 3.36 & 16.3 & 1.33 & 0.83 & 1.35 \\
$0^{\circ}$ & 0.067 & 4.01 & 19.4 & 1.57 & 0.86 & 1.00 \\
$30^{\circ}$ & 0.057 & 4.48 & 21.7 & 1.67 & 0.84 & 0.93 \\
$45^{\circ}$ & 0.046 & 5.10 & 24.7 & 1.71 & 0.86 & 0.81 \\
$60^{\circ}$ & 0.022 & 5.92 & 28.7 & 1.99 & 0.87 & 0.68 \\
\hline
\end{tabular}

\footnotetext{
${ }^{a}$ At the moment the pyrolysis front reaching the top of fuel, $x_{p}=20 \mathrm{~cm}$;

${ }^{b}$ Corresponding HRR per unit width at $x_{p}=20 \mathrm{~cm}$, with $\Delta H_{c}=24.2 \mathrm{~kJ} / \mathrm{g}$ [31].
}

Assuming a constant heat of combustion, $\Delta H_{c}$ the heat-release rate (HRR) per unit width of the burning material, $\dot{Q}^{\prime}$ is calculated as

$\dot{Q}^{\prime}=\dot{Q}^{\prime \prime} x_{p}=\Delta H_{c} \dot{m}^{\prime}=\left(\dot{m}^{\prime \prime} \Delta H_{c}\right) x_{p}$.

The flame length is therefore proportional to the HRR per unit width in the form of a power-law function, $x_{f}=$ $C \cdot\left(\dot{m}^{\prime}\right)^{p}=C^{\prime} \cdot\left(\dot{Q}^{\prime}\right)^{p}$ where the fitting index, $p$ is listed in Table 1 and plotted in Fig. 4. This relationship was first hypothesized by Delichatsios on the basis of dimensional analysis [30,33] and $p$ has been shown to match the theoretical value of $2 / 3$ for many large and turbulent wall fires [15]. Tsai and Drysdale, however have found that the $2 / 3$ scaling relationship does not satisfy experimental data from smaller wall fires, specifically where $\dot{Q}^{\prime}$ is less than about $20 \mathrm{~kW} / \mathrm{m}[34]$.

To understand this behavior, Gollner et al. [35] first presented Delichatsios' scaling analysis [30] by considering a turbulent wall plume with a constant entrainment coefficient $\alpha$, the ratio between the tangential entrained velocity and the buoyant upward velocity in the plume. If $f$ is the stoichiometric fuel-to air mass ratio, this mass balance gives

$\dot{m}^{\prime}=f x_{f} \alpha \rho_{a} u_{g}$,

where $\rho_{a}$ is the density of ambient air and $u_{g}=\sqrt{x_{f} g}$, the average vertical velocity in the buoyant plume. Solving for the flame length then reveals the scaling

$x_{f}=\left[\dot{m}^{\prime} /\left(\rho_{a} \alpha f \sqrt{g}\right)\right]^{2 / 3} \sim\left(\dot{Q}^{\prime}\right)^{2 / 3}$.

While this equation provides good results for large, turbulent wall fires, higher values of the index $p$ are found for lower HRR fires. In a laminar wall plume, it would be expected that oxygen will reach the reaction zone by molecular diffusion rather than turbulent mixing. As suggested by Gollner et al. [35], the inflow velocity, $\alpha u_{g}$ in Eq. 3 should therefore be modified to a diffusion velocity, formed by dividing the molecular diffusion coefficient, $D$ by an average diffusion distance, $a$. Roper [17] estimated this diffusion distance to be an average volume flow rate per unit width, $\dot{m} /\left(f \rho_{f}\right)$ (where $\rho_{f}$ is an average gas density in the flame), divided by an average buoyant velocity, $\sqrt{x_{f} g}$. Substituting these estimates into Eq. 3 yields

$x_{f}=\left(\dot{m}^{\prime}\right)^{4 / 3} /\left(\rho_{f} \rho_{a} f^{2} D \sqrt{g}\right)^{2 / 3} \sim\left(\dot{Q}^{\prime}\right)^{4 / 3}$.

While in vertical wall fire experiments Gollner et al. [35] found an intermediate value of $p \approx 1$ for corrugated cardboard and, for PMMA and a gas burner, Tsai and Drysdale [34] found $p=1 \sim 1.25$ depending on the configuration, this exponent has never before been found to approach its theoretical maximum of $4 / 3$ in a laminar flame. Similar values of index $p \approx 1$ were also found at $\theta=0^{\circ}$ and $30^{\circ}$ in this study (see Table 1). This is because realistic vertical-wall flames are unlikely to be perfectly laminar, resulting in values intermediate between these two correlations.

However, this limiting value of $p=4 / 3$ is found in this study for flame-spread experiments on the underside of a fuel surface (see $\theta<0^{\circ}$ in Fig. 4 and Table 1). Boundary-layer flows along the underside of a mildlyinclined plate are turbulence-suppressed by uprising air flow, which is further demonstrated by a much lower 


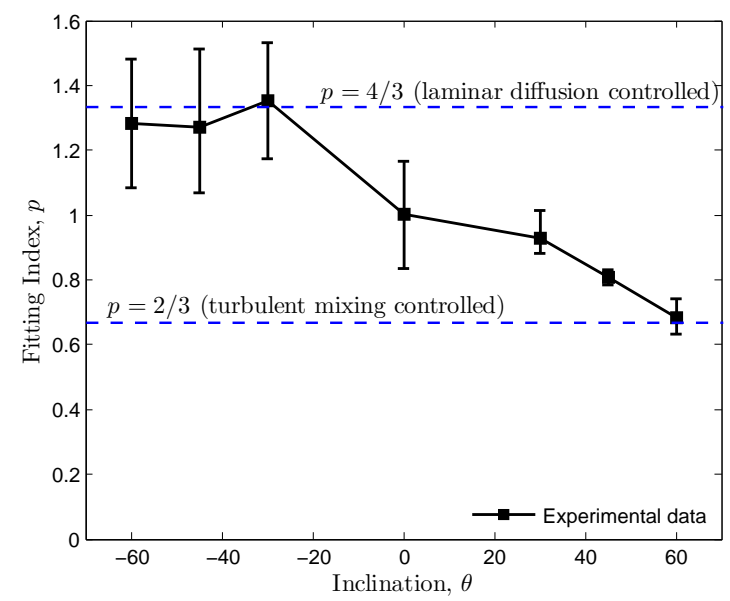

Fig. 4. The fitting index, $p$ as a function of inclination from $x_{f} \sim\left(\dot{Q}^{\prime}\right)^{p}$, where values have been calculated from $\sim 50 \mathrm{~s}$ after ignition through steady burning. Error bars denote the standard deviation of $p$ from several experiments and regions of spread and steady burning.

$\dot{Q}^{\prime}$ than the critical value $(\sim 20 \mathrm{~kW} / \mathrm{m})$ previously observed for an onset of transition to a turbulent wall-fire correlation, as shown in Table 1. Molecular diffusion is therefore dominant in the thin laminar flow on the underside of the fuel, corroborating why the fully laminar solution closely matches between $\theta=-60^{\circ} \sim$ $-30^{\circ}$. This perceived laminarization has also been observed by Zhang et al. [18], where reference was made to a later transition to turbulence observed in heat-transfer experiments with lower $\theta$. On the other hand, for flame spread over the top of a fuel surface $\theta>30^{\circ}$, boundary-layer separation is clearly observed (see Fig. 1b). Thus, turbulent mixing dominates, reflected by a rapid drop in $p$ with increasing $\theta$ that approaches the theoretical value of $2 / 3$. More details on flame separation will be discussed with regard to flame thickness and tilt angle in the following section.

\section{Flame Thickness and Tilt Angle}

In this section, the flame geometry is used to help explain both the increase in $\dot{m}^{\prime \prime}$ with $\theta$ and the decrease in $V_{p}$ between $\theta=0^{\circ} \sim 60^{\circ}$. In the $60^{\circ}$ case (Fig. 5a), the standoff distance of the flame, $y_{f}(x)$ significantly increases past the burning fuel surface, as buoyancy lifts hot gases. This process is three-dimensional, resulting in a thicker flame and a larger radiation view factor between the flame and fuel surface. Figure $5 \mathrm{~b}$ shows this flame thickness, $H$ defined as the maximum flame standoff distance, as a function of time during flame spread. Clearly, the flame thickness increases over time for all angles during spread until reaching a steady value after spread stops, corresponding to the steady-burning region, and these steady values are always increasing with $\theta$. Since the flame is observed to always attach to the burning (rapidly pyrolyzing) surface $\left(x<x_{p}\right)$, this results in a greater overall heat flux from the flame there, $\dot{q}_{b}^{\prime \prime}$ as the flame thickness increases. On the other hand, above the unburned (preheating) region $\left(x>x_{p}\right)$ flames are lifted away from the fuel surface, leading to much smaller convective flame heating (or even convective cooling by the cold inlet air) to offset this increase in radiation. The large drop in the spread rate at large inclination angles $(\theta>0$, Table 1) follows this perceived decrease in convective heating and suggests a smaller overall heat flux to the unburned region, $\dot{q}_{u}^{\prime \prime}$.

By correlating the flame length and thickness, the flame tilt (or liftoff) angle, $\phi$ becomes a useful parameter to describe the flame shape in order to forecast the rates of spread and burning at different inclinations. Due to intense fluctuations of the location of the flame tip with time, utilizing instantaneous measurements of the flame tip in flame tilt angle measurements results in significant scatter. For this reason, 10 continues sideview photos are averaged over one another in this study, dimming small fluctuations of the flame tip and intensifying the average location of the flame (Fig. 5a). The tilt angle is then defined by a line dividing this overlapped flame image into two regions with the same total luminance (the sum of the intensities of each 

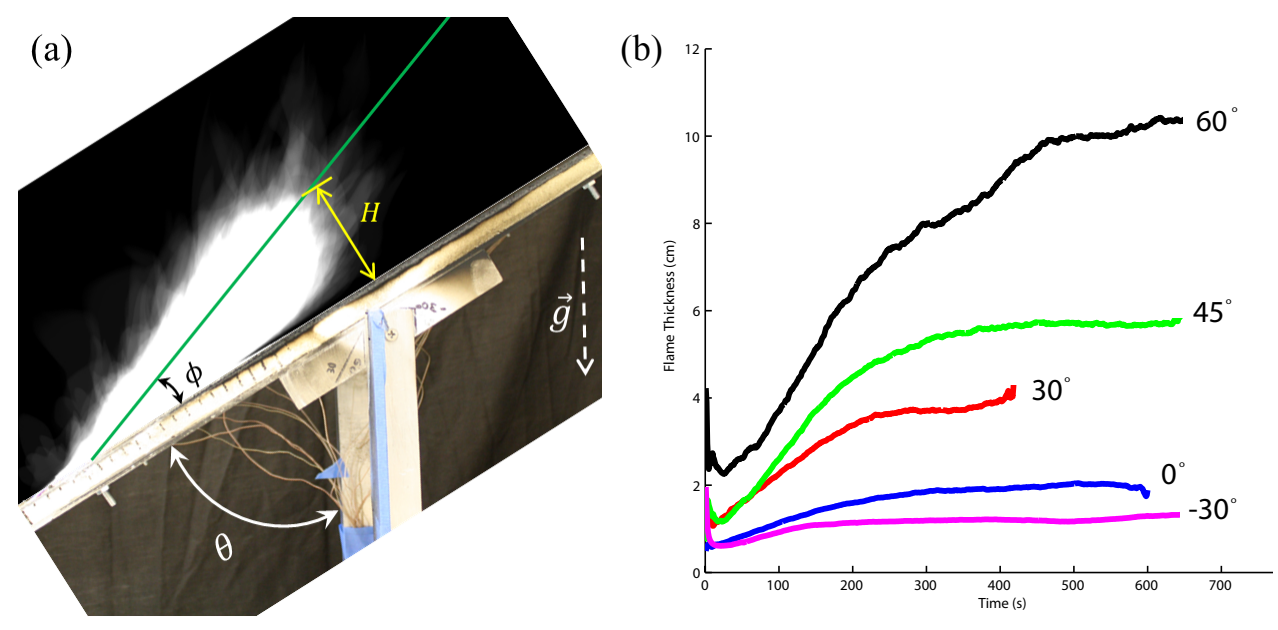

Fig. 5. (a) an overlapped flame image at $\theta=60^{\circ}$ with 10 continuous photos averaged together, in order to determine the flame thickness, $H$, and tilt angle, $\phi$, defined in this paper, and (b) measurements of the flame thickness varying with time under different inclinations.

pixel). Because the flame luminance corresponds with both flame temperatures and sooting conditions, it therefore connects in some manner to the radiance from the flame. This definition can be useful in estimating radiative heat fluxes and view factors, which were used in previous work [22] to analyze steady burning rates.

Figure 6a plots an average flame tilt angle over at least 3 repeating tests as a function of time for four inclinations. Note that for boundary-layer flames, the definition of the flame tilt angle becomes less meaningful as the peak standoff distance, $H$ occurs near the center of the flame length, not at the tip, as shown in Figs. $1 \mathrm{~b}$ and 2. Therefore, only values for $\theta \geq 0^{\circ}$ are shown in Fig. 6 . At $\theta=0^{\circ}$, the flame thickness, $y_{f}(x)$ increases much slower than the flame length $x_{f}$, so $\theta \sim y_{f}\left(x_{f}\right) / x_{f}$ decreases with time. The same situation occurs for negative inclinations (not shown here), with increasingly smaller, nearly-constant standoff distances (represented by $H$ in Fig. 5b). At $\theta=30^{\circ}$, the flame begins to separate from the surface of the fuel as the flame length increases (see Fig. 1b), reducing $\dot{q}_{u}^{\prime \prime}$ as demonstrated by a clear decrease in the flame-spread rate (Table 1 and Fig. 6b). Near this transition, these two competing effects make the tilt angle more closely approach a constant value
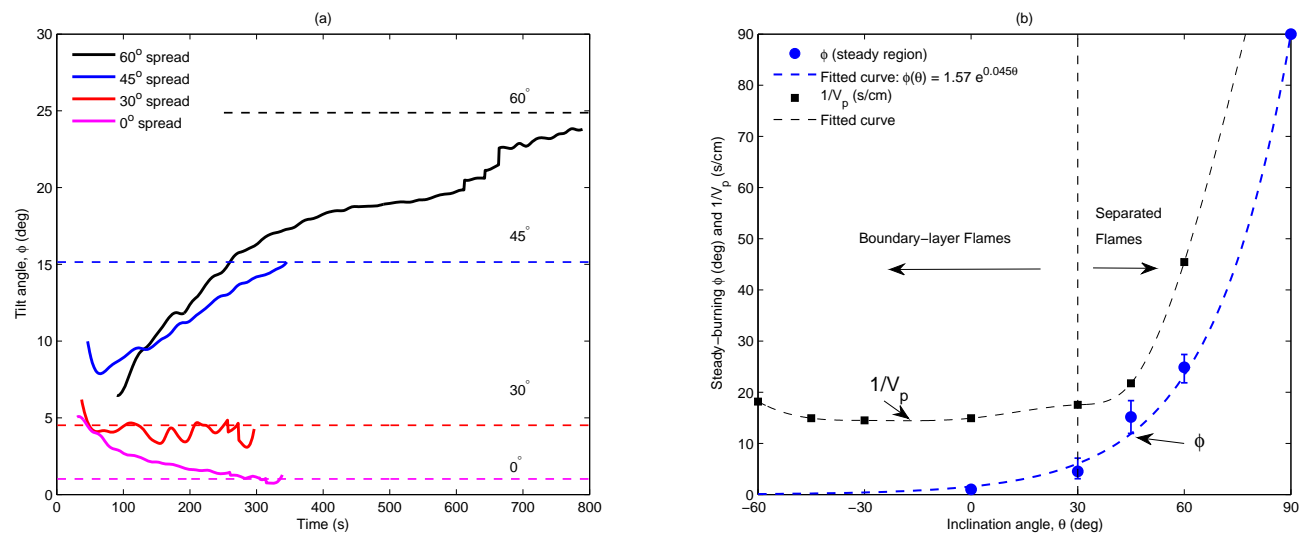

Fig. 6. (a) The tilt angle, $\phi$ plotted as a function of time during flame spread where $\theta=0^{\circ} \sim 60^{\circ}$. Dashed lines indicate the flame tilt angle achieved during steady burning, after $x_{p}=20 \mathrm{~cm}$. (b) The steady tilt angle during steady burning (circles) as a function of $\theta$, fitted by $\phi(\theta)=1.57 e^{0.045 \theta}$, and compared with the inverse of the flame-spread rate, $1 / V_{p}$ (squares) in Table 1. 
throughout the duration of the test. At $\theta=45^{\circ}$, a spike occurs in the beginning $(t<100 \mathrm{~s}$ ) of two (out of four) repeated tests, due to the slow development of a boundary layer after removing the insulation sheet used during ignition. Until the flame achieves a high enough HRR, it does not entrain sufficient air to stabilize the flow along the inclined surface, instead burning more like a free flame without regard to the adjacent inclined surface. In general, the trend of the tilt angle increasing with time (and therefore $x_{p}$ ) is clear for $\theta=45^{\circ}$ and $60^{\circ}$, which is most likely due to increasing heat-release and burning rates over time, introducing a stronger buoyant flow lifting the flame upwards, and enlarging the flame thickness, thus increasing the flame tilt angle.

As seen in Fig. $6 a$ and $b$, the average tilt angle achieved during steady burning (after $x_{p}=20 \mathrm{~cm}$ ) increases exponentially with $\theta$. In Fig. $6 \mathrm{~b}$, the tilt angle is shown to reach its theoretical maximum of $90^{\circ}$ at $\theta=90^{\circ}$ because the flame is perfectly symmetric when averaged over time (a pool fire). Values of the steady flame tilt angle can be well fitted as an exponential function $\phi(\theta)=1.57 e^{0.045 \theta}$, shown as a dotted line in Fig. $6 \mathrm{~b}$. As the buoyant force acting on the flame increases with increasing $\theta$, the vertical inclination of the flame exponentially increases as the influence of a restricted flow field from the inclined fuel surface diminishes. As the flame tilt angle and therefore the flame standoff distance increase with $\theta$, reduced heat fluxes will reach the unburnt fuel surface due to both a longer convective heating length and increased cold-flow entrainment from ahead of the flame front. These reduced heat fluxes with increasing $\theta$ should also slow the flame-spread rate with increasing $\theta$, resulting in an inverse relationship between the flame-spread rate and the flame tilt angle, $1 / V_{p} \sim \phi$. In Fig. $6 \mathrm{~b}$ this relationship is shown to be somewhat accurate, with $1 / V_{p}$ nearly-exponentially increasing towards its maximum value (minimum $V_{p}$ ) at $90^{\circ}$, which was measured for horizontal flame spread over PMMA by Drysdale and Macmillan [5]. The shape of the flame, especially once separated from the fuel surface, dominates the flame-spread process, which is well-represented by the flame tilt angle, $\phi$.

\section{CONCLUSION}

Parameters describing the time evolution of the flame geometry of spreading flames over an inclined fuel have been studied here, including both flame and pyrolysis lengths, the mass-loss rate and the flame tilt angle, all as a function of the fuel inclination, $\theta$. A power-law relationship between the flame and pyrolysis length, interestingly, was found to remain valid with the same exponent $\left(x_{f} \sim x_{p}^{0.85} \sim t^{0.85}\right)$ regardless of inclination. In addition, the continuously increasing constant $k$ in a linear fit between $x_{f}$ and $x_{p}$ reflected the increasing difference between the flame and pyrolysis lengths with increasing $\theta$.

The flame length was also related to the burning rate and HRR at different inclinations, revealing that the onset of transition between laminar to turbulent behavior would change through the inclination of the fuel surface. Underside flame spread $\left(\theta<0^{\circ}\right)$ was found to be turbulent-suppressed and closely follow the previously derived diffusion-controlled correlation, $x_{f} \sim\left(\dot{Q}^{\prime}\right)^{4 / 3}$. Meanwhile, for topside flame spread $\left(\theta>0^{\circ}\right)$, with increasing $\theta$ as well as HRR, the common turbulent-mixing correlation $x_{f} \sim\left(\dot{Q}^{\prime}\right)^{2 / 3}$ is approached. This result may be interesting for small-scale laboratory testing, where flame behavior may be appreciably modified towards laminar or turbulent, simply by inclining the fuel surface downwards or upwards, respectively.

Finally, time-evolution measurements of the flame tilt angle corroborated earlier observations of boundarylayer separation and flame-spread rates, and in particular showed that the inverse of the flame-spread rate, $1 / V_{p}$ follows the same trend with $\theta$ as the flame tilt angle. These results may be useful for forecasting flamespread rates or the HRR in the future.

\section{ACKNOWLEDGEMENTS}

The authors would like to acknowledge helpful comments from Forman Williams and Ali Rangwala during the first stage of this work and the assistance of Charles Marcacci, Jeanette Cobian and Ulrich Niemann for assistance with laboratory experiments.

\section{References}

[1] Orloff, L., de Ris, J., and Markstein, G. Upward turbulent fire spread and burning of fuel surface. Symposium (International) on Combustion, 15(1):183 - 192, 1975. http://dx.doi.org/10.1016/ 
[2] Saito, K., Quintiere, J., and Williams, F. A. Upward turbulent flame spread. Fire Safety Science, 1:75-86, 1985. http://dx.doi.org/10.3801/IAFSS.FSS.1-75.

[3] Zhou, L. and Fernandez-Pello, A. C. Turbulent burning of a flat fuel surface. Fire Safety Science - Proceedings of the Second International Symposium, International Association for Fire Safety Science, 3:415-424, 1991. http://dx.doi.org/10.3801/IAFSS.FSS.3-415.

[4] Fernandez-Pello, A. Downward flame spread under the influence of externally applied thermal radiation. Combustion Science and Technology, 17(1-2):1-9, 1977. http://dx.doi.org/10.1080/ 00102209708946807.

[5] Drysdale, D. and Macmillan, A. Flame spread on inclined surfaces. Fire Safety Journal, 18(3):245 - 254, 1992. http://dx.doi.org/10.1016/0379-7112(92)90018-8.

[6] Wu, Y., Xing, H., and Atkinson, G. Interaction of fire plume with inclined surface. Fire Safety Journal, 35(4):391 - 403, 2000. http://dx.doi.org/10.1016/S0379-7112(00)00032-1.

[7] Drysdale, D., Macmillan, A., and Shilitto, D. The king's cross fire: Experimental verification of the trench effect. Fire Safety Journal, 18(1):75 - 82, 1992. http://dx.doi.org/10.1016/0379-7112(92) 90048-H.

[8] Dupuy, J. L. Snumerical analysis of flame heating on arbitrarily oriented condensed fuel surfaces. International Journal of Wildland Fire, 5(3):153-164, 1995. http://dx.doi.org/10.1071/ WF9950153.

[9] Emori, R., Iguchi, I., Saito, K., and Wichman, I. Simplified scale modeling of turbulent flame spread with implication to wildland fires. Fire Safety Science, 2:263-273, 1988. http://dx.doi.org/ 10.3801/IAFSS.FSS.2-263.

[10] International, A. Astm e108-11 standard test methods for fire tests of roof coverings.

[11] Kashiwagi, T. and Newman, D. L. Flame spread over an inclined thin fuel surface. Combustion and Flame, 26:163 - 177, 1976. http://dx.doi.org/10.1016/0010-2180(76)90069-9.

[12] Ito, A. and Kashiwagi, T. Characterization of flame spread over pmma using holographic interferometry sample orientation effects. Combustion and Flame, 71(2):189 - 204, 1988. http: //dx.doi.org/10.1016/0010-2180(88)90007-7.

[13] Pizzo, Y., Consalvi, J., Querre, P., Coutin, M., and Porterie, B. Width effects on the early stage of upward flame spread over pmma slabs: Experimental observations. Fire Safety Journal, 44(3):407 - 414, 2009. http://dx.doi.org/10.1016/j.firesaf.2008.09.003.

[14] Xie, W. and DesJardin, P. E. An embedded upward flame spread model using 2d direct numerical simulations. Combustion and Flame, 156(2):522 - 530, 2009. http://dx.doi.org/10.1016/j. combustflame.2008.11.011.

[15] Quintiere, J. G. The effects of angular orientation on flame spread over thin materials. Fire Safety Journal, 36(3):291 - 312, 2001. http://dx.doi.org/10.1016/S0379-7112(00)00051-5.

[16] Ahmad, T. and Faeth, G. Turbulent wall fires. Symposium (International) on Combustion, 17(1):1149 - 1160, 1979. http://dx.doi.org/10.1016/S0082-0784(79)80109-5.

[17] Roper, F., Smith, C., and Cunningham, A. The prediction of laminar jet diffusion flame sizes: Part ii. experimental verification. Combustion and Flame, 29(0):227 - 234, 1977. http://dx.doi.org/10. 1016/0010-2180(77)90113-4.

[18] Zhang, Y., Bustamante, M., Gollner, M., Sunderland, P., and Quintiere, J. Burning on flat wicks at various orientations. Journal of Fire Sciences, 2013. under review. 

teristics of a condensed fuel: effect of angular orientation of fuel surface. Combustion Theory and Modelling, 14(4):495-518, 2010. http://dx.doi.org/10.1080/13647830.2010.499965.

[20] Ali, S. M., Raghavan, V., and Rangwala, A. S. Numerical analysis of flame heating on arbitrarily oriented condensed fuel surfaces. Fire Safety Journal, 49(0):67 - 78, 2012. http://dx.doi.org/10. 1016/j.firesaf.2011.12.004.

[21] de Ris, J. and Orloff, L. The role of buoyancy direction and radiation in turbulent diffusion flames on surfaces. Symposium (International) on Combustion, 15(1):175 - 182, 1975. http://dx.doi.org/ 10.1016/S0082-0784(75)80295-5.

[22] Gollner, M. J. Studies on upward flame spread. PhD thesis, University of California San Diego, 2012. http://www.escholarship.org/uc/item/4f41b6xr.

[23] Gollner, M., Huang, X., Cobian, J., Rangwala, A., and Williams, F. Experimental study of upward flame spread of an inclined fuel surface. Proceedings of the Combustion Institute, 34(2):2531 2538, 2013. http://dx.doi.org/10.1016/j.proci.2012.06.063.

[24] Smith, D. Measurements of flame length and flame angle in an inclined trench. Fire Safety Journal, 18(3):231 - 244, 1992. http://dx.doi.org/10.1016/0379-7112(92)90017-7.

[25] Pizzo, Y., Consalvi, J., and Porterie, B. A transient pyrolysis model based on the b-number for gravity-assisted flame spread over thick pmma slabs. Combustion and Flame, 156(9):1856 - 1859, 2009. http://dx.doi.org/10.1016/j.combustflame.2009.06.007.

[26] Zhang, Y., Ji, J., Wang, Q., Huang, X., Wang, Q., and Sun, J. Prediction of the critical condition for flame acceleration over wood surface with different sample orientations. Combustion and Flame, 159(9):2999 - 3002, 2012. http://dx.doi.org/10.1016/j.combustflame.2012.04.007.

[27] Alexander, M. E. Calculating and interpreting forest fire intensities. Canadian Journal of Botany, 60:349-357, 1982. http://cfs.nrcan.gc.ca/publications/?id=21396.

[28] Hu, L., Liu, S., de Ris, J. L., and Wu, L. A new mathematical quantification of wind-blown flame tilt angle of hydrocarbon pool fires with a new global correlation model. Fuel, 106(0):730 - 736, 2013. http://dx.doi.org/10.1016/j.fuel.2012.10.075.

[29] Consalvi, J., Pizzo, Y., Porterie, B., and Torero, J. On the flame height definition for upward flame spread. Fire Safety Journal, 42(5):384 - 392, 2007. http://dx.doi.org/10.1016/j.firesaf.2006.12.008.

[30] Delichatsios, M. A. Flame heights in turbulent wall fires with significant flame radiation. Combustion Science and Technology, 39(1-6):195-214, 1984. http://dx.doi.org/10.1080/ 00102208408923789.

[31] Quintiere, J. Fundamentals of fire phenomena. John Wiley, 2006.

[32] Glassman, I. and Yetter, R. Combustion. Elsevier Science, 2008.

[33] Delichatsios, M. Turbulent convective flows and burning on vertical walls. Proceedings of the Combustion Institute, 19(1):855-868, 1983. http://dx.doi.org/10.1016/S0082-0784(82)80261-0.

[34] Tsai, C. K. and Drysdale, D. Flame height correlation and upward flame spread modelling. Fire and Materials, 26(6):279-287, 2002. http://dx.doi.org/10.1002/fam.809.

[35] Gollner, M., Williams, F., and Rangwala, A. Upward flame spread over corrugated cardboard. Combustion and Flame, 158(7):1404 - 1412, 2011. http://dx.doi.org/10.1016/j.combustflame.2010. 12.005 . 